\title{
Produção e qualidade de três tipos de melão, variando o número de frutos por planta ${ }^{1}$
}

\author{
Graciela Maiara Dalastra ${ }^{2 *}$, Márcia de Moraes Echer ${ }^{2}$, Élcio Silvério Klosowski², Tiago Luan Hachmann²
}

10.1590/0034-737X201663040013

\section{RESUMO}

O melão (Cucumis melo L.) tem grande importância para a economia nacional, fazendo-se necessário o conhecimento sobre as práticas de manejo adequadas, de modo a facilitar a condução de sua cultura, sem comprometer a produtividade e a qualidade dos frutos. O objetivo deste trabalho foi avaliar a qualidade físico-química e a produtividade de três tipos de melão, conduzidos com um e dois frutos por planta. O experimento foi realizado de setembro a dezembro de 2013, no Setor de Cultivo Protegido, da Unioeste, Campus de Marechal Cândido Rondon. O delineamento adotado foi o de blocos ao acaso, em esquema fatorial 3 x 2, com seis repetições. No primeiro fator, foram alocados os tipos de melão (Amarelo, Rendilhado e Pele de Sapo) e, no segundo, o número de frutos (um e dois frutos por planta). Os frutos foram avaliados quanto à massa média, aos diâmetros transversal e longitudinal do fruto e do lóculo, à espessura da polpa, ao índice de formato do fruto e do lóculo, aos sólidos solúveis, ao pH, à acidez titulável, à firmeza, à ratio e à produtividade. Frutos obtidos de plantas conduzidas com um e dois frutos apresentam maior massa média e maior produtividade, respectivamente. Melões do tipo pele de sapo apresentaram maior massa média de fruto e maior produtividade. A ratio foi influenciada pelo número de frutos mantidos por planta, para melão do tipo amarelo. Melão do tipo rendilhado apresentou redução de acidez, em comparação com a dos demais tipos, independentemente do número de frutos por planta. A maior espessura da polpa foi encontrada em frutos de plantas conduzidas com um fruto por planta. Os índices de formato do fruto e do lóculo não foram influenciados pelo número de frutos por planta. Independentemente do número de frutos e do tipo de melão, o teor de sólidos solúveis foi superior ao mínimo recomendado para comercialização.

Palavras-chave: Cucumis melo L.; melão rendilhado; melão amarelo; melão pele de sapo; raleio de frutos.

\section{ABSTRACT}

\section{Yield and quality of three types of melon, varying the number of fruits per plant}

The purpose of this study was to evaluate the characteristics of yield and quality of three types of melon, bearing one and two fruits per plant. The experiment was conducted from September to December 2013, in the Greenhouse Sector belonging to Unioeste, Campus Marechal Cândido Rondon - PR. The experimental design wasrandomized blocks in a factorial scheme $3 \times 2$, with six replications. In the first factor the melon types (canary melon, net melon, frog skin melon) were allocated and in the second factor, the plants with different number of fruits (one and two fruits per plant). The characteristics evaluated were fruit mass, longitudinal and transversal diameters of fruit and locule, thickness of the endocarp, fruit and locule shape index, soluble solids, $\mathrm{pH}$, titratable acidity, fruit firmness, ratio and productivity. The fruits obtained from plants with one and two fruits showed higher fruit fresh mass and increased productivity,

\footnotetext{
Submetido em 10/06/2014 e aprovado em 22/10/2015.

${ }^{1}$ Parte da dissertação de mestrado da primeira autora.

${ }^{2}$ Universidade Estadual do Oeste do Paraná, Centro de Ciências Agrárias, Marechal Cândido Rondon, Paraná, Brasil. gradalastra@hotmail.com; mmecher@bol.com.br; elciosk1@yahoo.com.br; tiagohach@gmail.com

"Autora para correspondência: gradalastra@hotmail.com
} 
respectively. The frog skin melon type had higher fresh fruit mass and productivity. The ratio was influenced by the number of fruits per plant for the canary melon type. The net melon type showed a reduction in acidity compared to the other types, regardless of the number of fruits maintained per plant. The thickened pulp was found in fruits of plants with only one fruit. The fruit and locule shape index were not influenced by the number of fruits per plant. Regardless of the number of fruits and the type of melon, the soluble solids content was higher than the minimum recommended for marketing.

Key words: Cucumis melo L.; net melon; canary melon; frog skin melon; fruit pruning.

\section{INTRODUÇÃO}

O meloeiro (Cucumis melo L.) é uma espécie da família das cucurbitáceas, de clima tropical, originário dos quentes vales do Irã e do noroeste da Índia (Filgueira, 2008).

Essa olerícola tem grande importância econômica no mercado brasileiro, sendo uma das culturas de maior crescimento nas exportações de produtos hortícolas pelo país. O Brasil ocupa a décima segunda colocação na escala de produção mundial, sendo o maior produtor de melão da América do Sul. A região nordeste, com o cultivo a céu aberto, é responsável por 91,55\% da produção (IBGE, 2012). Além do valor econômico e alimentar, as cucurbitáceas também têm grande importância social na geração de empregos diretos e indiretos, pois demandam grande quantidade de mão de obra em todas as etapas de seus sistemas de produção.

O número de frutos por planta é um dos componentes mais importantes para a definição da produtividade do meloeiro. As plantas desta espécie, quando cultivadas em ambiente protegido, produzem de um a três frutos, por causa do abortamento natural. Além de alta produtividade, espera-se que os frutos tenham boa qualidade, relacionada com o manejo que a cultura recebe durante o seu ciclo, do qual dependerá o teor de sólidos solúveis (Chitarra \& Chitarra, 2005).

Essa mudança no número de frutos por planta altera a qualidade dos frutos, pois pode modificar a razão da área foliar por fruto, alterando desta forma a relação fontedreno (Queiroga et al., 2008). De acordo com Queiroga et al. (2008), o aumento do número de frutos por planta leva a uma competição por assimilados entre drenos e resulta na redução do peso de cada fruto e do teor de sólidos solúveis de sua polpa.

Os melões pertencentes ao grupo dos aromáticos, como é o caso do tipo rendilhado, são os preferidos pelos consumidores. Por isso, tem aumentado o interesse dos produtores em diversificar o produto a ser oferecido para os mercados interno e externo, pela introdução de diversos genótipos de melão, especialmente do tipo rendilhado, do cantaloupensis e do tipo gália (Nunes et al., 2004).

Diante da importância que a cultura tem para a economia nacional, faz-se necessário o conhecimento sobre os efeitos da prática de raleio de frutos, de forma a facilitar o manejo da cultura, sem comprometer a produtividade e a qualidade dos frutos, além da escolha de tipos de melão que melhor se adaptam à região de cultivo, considerandose a produtividade, os aspectos de comercialização e a resistência a pragas e doenças.

Desta forma, na hipótese de que o número de frutos e o tipo de melão podem influenciar na produtividade e na qualidade da cultura, este trabalho teve por objetivo avaliar a qualidade físico-química e a produtividade de frutos de meloeiro do tipo amarelo, rendilhado e pele de sapo, conduzido com um e dois frutos por planta, sob condições de ambiente protegido.

\section{MATERIAL E MÉTODOS}

O experimento foi realizado de setembro a dezembro de 2013, em cultivo protegido, na Estação de Horticultura e Controle Biológico Professor Mário César Lopes, pertencente ao Núcleo de Estações Experimentais da Universidade Estadual do Oeste do Paraná, campus de Marechal Cândido Rondon, Paraná. O ambiente protegido, utilizado nesse experimento, era composto por teto em arco, revestido com filme de polietileno de baixa densidade (150 $\mu$ de espessura), com as laterais protegidas por tela branca com $40 \%$ de sombreamento. Na porção central desse ambiente foi instalado, em abrigo meteorológico, a uma altura de 1,20 m, um Datalogger da marca Homis modelo 494, com sensores de temperatura e de umidade relativa do ar. Os registros de temperatura e de umidade relativa do ar foram realizados a cada hora (Figura 1).

O delineamento experimental adotado foi de blocos ao acaso, em esquema fatorial $3 \times 2$, com seis repetições. $\mathrm{O}$ primeiro fator foi constituído de três tipos de melão (amarelo, rendilhado e pele de sapo) e o segundo fator correspondeu ao número de frutos por planta (um e dois frutos).

A semeadura foi realizada em bandejas de poliestireno expandido, de 128 células, com substrato comercial. As bandejas permaneceram em casa de vegetação até o momento do transplantio, que ocorreu quando as plantas apresentavam a segunda folha verdadeira. 
A cultura foi instalada em vasos de 12 litros, dispostos no espaçamento de 1,20 m entre linhas e $0,5 \mathrm{~m}$ entre plantas. Os vasos foram preenchidos com mistura de substrato comercial para hortaliças e húmus, em proporções iguais, sendo transplantada uma muda por vaso. Para caracterização química da mistura utilizada, foi coletada uma amostra, cujos resultados encontrados foram: $\mathrm{pH}$ em $\mathrm{CaCl}_{2}=4,87 ; \mathrm{MO}=51,95 \mathrm{~g} \mathrm{dm}^{-3} ; \mathrm{H}+\mathrm{Al}=4,02 \mathrm{cmol}_{\mathrm{c}} \mathrm{dm}^{-3}$; $\mathrm{P}=14,27 \mathrm{mg} \mathrm{dm}^{-3} ; \mathrm{K}=3,25 \mathrm{mmol} \mathrm{dm}^{-3} ; \mathrm{Ca}^{2+}=3,41 \mathrm{cmol}_{\mathrm{c}}$ $\mathrm{dm}^{-3} ; \mathrm{N}=0,826 \mathrm{cmol}_{\mathrm{c}} \mathrm{dm}^{-3} ; \mathrm{Mg}^{2+}=3,17 \mathrm{cmol}_{\mathrm{c}} \mathrm{dm}^{-3} ; \mathrm{SB}=6,9$ $\mathrm{cmol}_{\mathrm{c}} \mathrm{dm}^{-3} ; \mathrm{CTC}=10,92 \% ; \mathrm{V} \%=63,18 ; \mathrm{Cu}=15,33 \mathrm{mg} \mathrm{dm}$ 3; $\mathrm{Zn}=60,26 \mathrm{mg} \mathrm{dm}^{-3} ; \mathrm{Mn}=9,70 \mathrm{mg} \mathrm{dm}^{-3} ; \mathrm{Fe}=30,98 \mathrm{mg}$ $\mathrm{dm}^{-3}$.

A irrigação foi realizada por gotejamento, utilizandose fita flexível com emissores espaçados em $0,50 \mathrm{~m}$ e vazão de $1,6 \mathrm{~L} \mathrm{~h}^{-1}$. A quantidade de água demandada foi controlada por meio de tensiômetros do modelo WATERMETER WS-76 (P*), que foram instalados dentro dos vasos, a uma profundidade de $20 \mathrm{~cm}$. Quando a tensão do substrato atingia $34,66 \mathrm{kPa}$, efetuava-se a irrigação, de acordo com a recomendação do fabricante. A adubação foi realizada por via de fertirrigação, duas vezes por semana, seguindo a recomendação de Trani et al. (2011), adaptada para este experimento, obedecendo os estádios de desenvolvimento da cultura. Durante o ciclo da cultura, foram aplicados $7,47 \mathrm{~kg}$ de fosfato monopotássico, 56,29 $\mathrm{kg}$ de nitrato de potássio, $26,75 \mathrm{~kg}$ de nitrato de cálcio, $28,92 \mathrm{~kg}$ de sulfato de magnésio e $1 \mathrm{~kg}$ de ácido bórico.

As plantas foram conduzidas verticalmente, em haste única, com uso de fitilhos plásticos até a altura de 1,80 m do solo, quando se realizou a poda do ponteiro. O tratamento de número de frutos foi fixado nos ramos secundários, emitidos entre o quarto e sexto entrenós. Quando os frutos apresentaram 3 a $4 \mathrm{~cm}$ de diâmetro, seus ramos foram podados, duas folhas após o ponto de inserção do fruto na haste. Todas as demais ramificações foram mantidas com uma folha.

Para auxiliar na polinização, foi colocada uma colmeia de abelha (Apis mellifera) na entrada do ambiente. O controle de pragas foi realizado de acordo com a necessidade da cultura, sendo realizadas duas aplicações de inseticidas (imidacloprido e $\beta$-ciflutrina) para efetuar o controle de pulgão-verde (Myzus persicae), tripes (Thrips tabaci) e mosca-branca (Bemisia tabaci raça B). Essas aplicações foram realizadas aos 10 e 37 dias após o transplante (DAT), seguindo-se as recomendações para a cultura.

A colheita iniciou-se aos 52 DAT e prolongou-se até 72 DAT, sendo realizada de acordo com a maturidade dos frutos, que variou para cada tipo. O ponto de colheita foi determinado pela mudança de coloração do epicarpo e,ou, pela formação de uma camada de abscisão junto ao pedúnculo do fruto. Depois de colhidos, os frutos foram levados para laboratório, onde inicialmente foram mensurados a massa média e os diâmetros transversal e longitudinal dos frutos. Os frutos foram então cortados ao meio e foram determinados os diâmetros transversal e longitudinal do lóculo e a espessura do endocarpo (polpa), com paquímetro digital. Além disso, foi medida a firmeza $(\mathrm{N})$ em pontos distintos (regiões central e equatorial dos frutos), com penetrômetro manual.

O teor de sólidos solúveis ( $\left.{ }^{\circ} \mathrm{Brix}\right)$ e o $\mathrm{pH}$ foram determinados por leitura direta no extrato do suco, com refratômetro e peagâmetro digitais, respectivamente.

Para determinação da acidez titulável (AT), foi pipetada uma alíquota de $20 \mathrm{~mL}$ de extrato do suco e acrescidos 30 $\mathrm{mL}$ de água, juntamente com três gotas do indicador fenolftaleína alcoólica, a 1\%. Foi então realizada a titulação com hidróxido de sódio, a $0,1 \mathrm{~N}$, até o ponto de viragem,
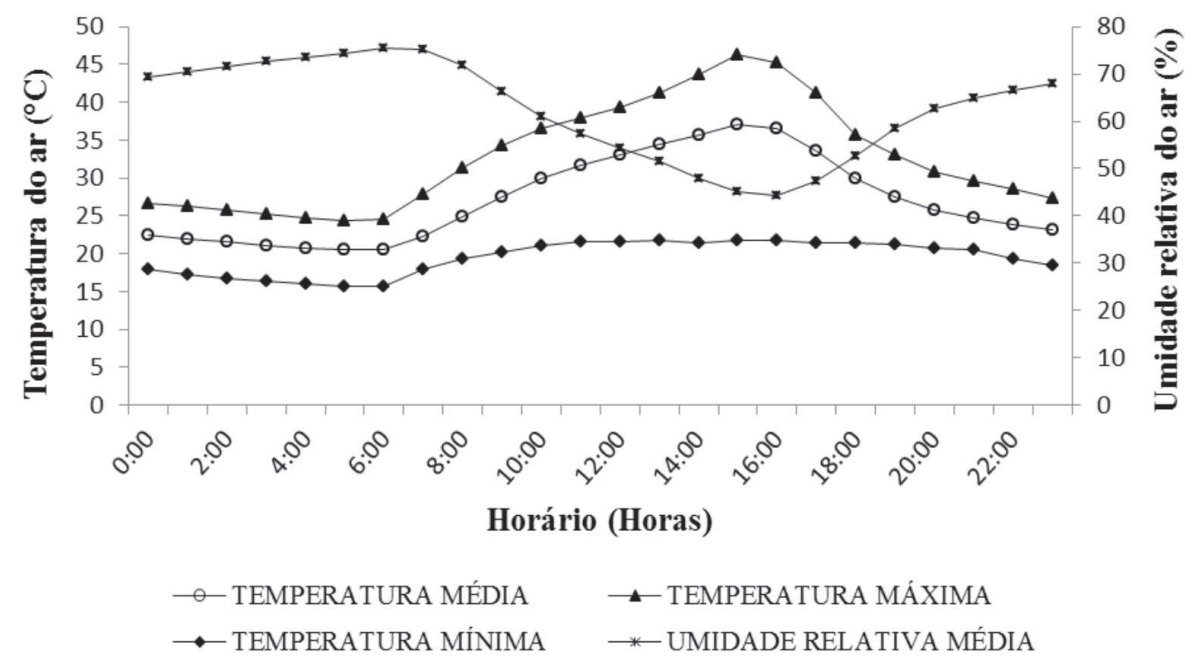

Figura 1: Valores médio, mínimo e máximo de temperatura do ar e médio de umidade relativa do ar por horário de observação, durante o ciclo de três tipos de melão. 
sendo os resultados expressos em \% de ácido cítrico, conforme metodologia proposta pelo Instituto Adolfo Lutz (2005).

$\mathrm{O}$ índice de formato do fruto foi determinado pela relação entre os diâmetros longitudinal e transversal do fruto; o índice de formato do lóculo foi obtido por meio da relação entre os diâmetros longitudinal e transversal do lóculo e, o índice de maturação (RATIO), por meio da relação entre sólidos solúveis e acidez titulável (SS/AT). Por fim, foi estimada a produtividade $\left(\mathrm{kg} \mathrm{m}^{-2}\right)$.

Os dados foram submetidos à análise de variância e as médias comparadas pelo teste de Tukey, a 5\% de significância, utilizando-se o programa estatístico SISVAR 5.3 (Ferreira, 2011).

\section{RESULTADOS E DISCUSSÃO}

A variação média da temperatura do ar no interior do ambiente manteve-se dentro dos limites críticos da cultura ao longo do ciclo, que, conforme Ancelotti \& Costa (2010), situa-se entre 24 e $32{ }^{\circ} \mathrm{C}$, sendo que a condição extrema de temperatura mínima é de $12^{\circ} \mathrm{C}$ e, a máxima, de $37^{\circ} \mathrm{C}$ (Figura 1).

Durante o período, as temperaturas mínimas registradas não foram prejudiciais para a cultura, pois somente às cinco e às seis horas foram registradas temperaturas próximas ao limite inferior $\left(15,7^{\circ} \mathrm{C}\right)$, consideradas prejudiciais ao desenvolvimento do meloeiro. No entanto, as temperaturas máximas $\left(37,9\right.$ a $\left.46,2^{\circ} \mathrm{C}\right)$, registradas durante o período das 11 às 17 horas permaneceram acima do limite superior da cultura, que, de acordo com Ancelotti \& Costa (2010), é de $37{ }^{\circ} \mathrm{C}$, podendo causar problemas na maturação dos frutos.

A umidade relativa média do ar variou de 44 a $75 \%$ (Figura 1). Valores abaixo de $50 \%$ de umidade relativa foram registrados das 13 às 17 horas, período em que se observou aumento da temperatura do ar (Figura 1). Essas condições de baixa umidade relativa do ar e de alta temperatura podem ter promovido o aumento da taxa transpiratória, ocasionando o fechamento estomático e, desta forma, reduzindo a atividade fotossintética das plantas.

Foram verificadas diferenças significativas para todas as variáveis. Foi observada interação entre os tipos de melão e o número de frutos por planta, para acidez titulável e ratio (Tabela 1), sendo as demais variáveis estudadas isoladamente (Tabelas 2 e 3 ).

Houve efeito significativo dos tipos de melão para massa média dos frutos, diâmetros longitudinal e transversal do fruto, diâmetros longitudinal e transversal do lóculo, produtividade, índice de formato do fruto, índice de formato do lóculo, $\mathrm{pH}$, sólidos solúveis e firmeza da polpa (Tabela 2). O número de frutos por planta influenciou significativamente a massa média dos frutos, os diâmetros longitudinal e transversal do fruto, os diâmetros longitudinal e transversal do lóculo, a espessura da polpa, a produtividade, os sólidos solúveis e o pH (Tabela 3 ).

O tipo rendilhado apresentou o menor valor de acidez, independentemente do número de frutos. Para os demais tipos, não foram encontradas diferenças para acidez titulável entre os diferentes números de frutos por planta (Tabela 1).

Com relação ao número de frutos, a menor acidez titulável foi obtida em melões do tipo rendilhado quando estes foram cultivados com dois frutos por planta (Tabela 1). Segundo Godoy \& Cardoso (2003), a ausência de diferença de acidez titulável deve-se ao fato de que, ao longo do ciclo, ocorre grande acúmulo de ácido cítrico, que serve como reserva para o fruto, podendo ser utilizado no processo respiratório ou na conversão em açúcares.

Ao avaliar a qualidade de cinco híbridos de melão rendilhado, com dois e três frutos por planta, Castoldi et al. (2008) verificaram que a quantidade de frutos por planta não interferiu na acidez titulável. Porém, Costa et al. (2004) e Purquerio \& Cecílio Filho (2005) observaram que a acidez titulável dos frutos foi menor em plantas conduzidas com apenas dois frutos do que em plantas com fixação livre de frutos.

Os diferentes resultados obtidos para acidez podem estar relacionados com as condições de cultivo e com os diferentes tipos utilizados. No entanto, observou-se, neste trabalho, que o tipo rendilhado apresenta menor teor de sólidos solúveis e de acidez quando as plantas são conduzidas com dois frutos (Tabela 1).

Em plantas conduzidas com um fruto, a maior ratio dos frutos foi observada para os tipos de melão amarelo e rendilhado. Quando conduzidos dois frutos por planta, a maior ratio foi observada para o melão tipo rendilhado. Em relação ao número de frutos por planta, o melão tipo amarelo, com um fruto por planta, resultou em frutos com maior ratio do que a de frutos de plantas com dois frutos, enquanto não foram observadas diferenças para o melão tipo rendilhado e para o pele de sapo (Tabela 1).

Para os tipos rendilhado e pele de sapo, a ratio não foi influenciada pelo número de frutos por planta. O resultado obtido indica que as variações que ocorreram para acidez titulável e teor de sólidos solúveis dos frutos não foram tão marcantes a ponto de causar alterações significativas na ratio.

Os maiores valores de massa média dos frutos, de diâmetro longitudinal de frutos, de diâmetros longitudinal e transversal de lóculo, de produtividade, de índice de formato do lóculo e de índice de formato do fruto foram observados para os frutos de melão do tipo pele de sapo, quando comparado com os dos tipos rendilhado e amarelo (Tabela 2). 
Para o tipo pele de sapo, Nunes et al. (2011), ao avaliarem a divergência genética entre linhagens de melão desse tipo, encontraram valores superiores aos deste estudo para a massa média dos frutos, variando de 2,02 a 3,44 kg. Segundo esses autores, o tamanho do fruto do melão do tipo pele de sapo é muito importante, uma vez que, ao contrário dos demais tipos de melão, o mercado consumidor exige frutos com massa acima de $3 \mathrm{~kg}$.

A massa média do fruto para melão do tipo amarelo (1083,47 g) está dentro do intervalo de massa (950 a 1987 g), obtido por Nunes et al. (2004), para híbridos desse tipo. Os valores da massa média dos frutos de melão do tipo rendilhado, obtidos neste trabalho foram semelhantes aos observados por Vargas et al. (2013) e Charlo et al. (2009), que variaram de 0,568 a 1,112 kg e 1,16 a 1,38 kg, respectivamente.

A variação de massa média dos frutos que ocorreu entre os tipos de melão é normal, pois cada tipo de melão apresenta características diferentes, tanto com relação às dimensões dos frutos quanto à própria massa média.

Para os diâmetros longitudinal e transversal do lóculo, os maiores valores foram observados para o tipo pele de sapo, em comparação com os dos tipos rendilhado e amarelo (Tabela 2). Segundo Charlo et al. (2009), frutos com tamanhos menores podem resultar em menores diâmetros longitudinais e transversais do lóculo e frutos com cavidades internas menores apresentam maior resistência ao transporte e ao manuseio. O valor de diâmetro longitudinal do lóculo $(7,63 \mathrm{~cm})$, obtido para melão do tipo rendilhado, foi semelhante ao obtido por Charlo et al. (2009) $(7,91 \mathrm{~cm})$.

O maior índice de formato do lóculo foi observado para os frutos de melão do tipo pele de sapo. Esses resultados estão coerentes, pois os frutos que apresentaram os maiores valores para o diâmetro longitudinal e transversal do lóculo resultaram em maior índice de formato do lóculo (Tabela 2).

O índice de formato de lóculo para o melão rendilhado $(1,81)$ foi maior que os obtidos por Charlo et al. (2009) para esse tipo de melão (1,29 a 1,5); no entanto, esses autores obtiveram frutos com menores dimensões, justificando desta forma os menores valores desse índice.

Melões dos tipos pele de sapo e rendilhado apresentaram maior diâmetro transversal dos frutos, quando comparados com o do tipo amarelo (Tabela 2).

Os melões do tipo pele de sapo apresentam maior tamanho e são mais alongados que os outros tipos de melão (amarelo e rendilhado), que são mais arredondados,

Tabela 1: Acidez titulável (AT) e índice de maturação $(R A T I O)$ em função do número de frutos por planta e do tipo de melão

\begin{tabular}{|c|c|c|c|c|c|c|}
\hline \multirow{3}{*}{$\begin{array}{l}\text { Número } \\
\text { de frutos }\end{array}$} & \multicolumn{3}{|c|}{ AT (\% ác. cítrico) } & \multicolumn{3}{|c|}{ RATIO } \\
\hline & \multicolumn{3}{|c|}{ Tipos } & \multicolumn{3}{|c|}{ Tipos } \\
\hline & Amarelo & Rendilhado & Pele de sapo & Amarelo & Rendilhado & Pele de sapo \\
\hline Um fruto & $0,23 \mathrm{aA}$ & $0,20 \mathrm{aB}$ & $0,24 \mathrm{aA}$ & $62,20 \mathrm{aA}$ & $62,54 \mathrm{aA}$ & $55,93 \mathrm{aB}$ \\
\hline Dois Frutos & $0,24 \mathrm{aA}$ & $0,17 \mathrm{bB}$ & $0,24 \mathrm{aA}$ & $52,99 \mathrm{bB}$ & $68,70 \mathrm{aA}$ & $55,59 \mathrm{aB}$ \\
\hline $\mathrm{CV}(\%)$ & \multicolumn{3}{|c|}{4,39} & \multicolumn{3}{|c|}{5,74} \\
\hline
\end{tabular}

*Médias seguidas de mesma letra, minúscula na coluna e maiúscula na linha, não diferem entre si pelo teste de Tukey (p < 0,05).

Tabela 2: Massa média dos frutos (MMF), diâmetro longitudinal do fruto (DLF), diâmetro transversal do fruto (DTF), diâmetro longitudinal do lóculo (DLL), diâmetro transversal do lóculo (DTL), produtividade (PROD), índice de formato do lóculo (IFL), índice de formato do fruto (IFF), pH, sólidos solúveis (SS), espessura da polpa (EP) e firmeza da polpa (F), em função do tipo de melão

\begin{tabular}{|c|c|c|c|c|c|c|}
\hline \multirow{2}{*}{ Tipos } & MMF & DLF & DTF & DLL & DTL & PROD \\
\hline & g & $\mathrm{cm}$ & $\mathrm{cm}$ & $\mathrm{cm}$ & $\mathrm{cm}$ & $\mathrm{kg} \mathrm{m}^{-2}$ \\
\hline Amarelo & $1083,47 \mathrm{~b}$ & $14,98 \mathrm{~b}$ & $11,65 \mathrm{~b}$ & $8,25 \mathrm{~b}$ & $4,27 \mathrm{~b}$ & $2,30 \mathrm{c}$ \\
\hline Rendilhado & $1182,09 \mathrm{~b}$ & $14,27 \mathrm{~b}$ & $12,71 \mathrm{a}$ & $7,63 \mathrm{~b}$ & $4,30 \mathrm{~b}$ & $2,80 \mathrm{~b}$ \\
\hline Pele de sapo & $1522,02 \mathrm{a}$ & $18,63 \mathrm{a}$ & $12,67 \mathrm{a}$ & $11,26 \mathrm{a}$ & $4,70 \mathrm{a}$ & $3,22 \mathrm{a}$ \\
\hline $\mathrm{CV}(\%)$ & 8,17 & 5,28 & 4,40 & 8,13 & 6,97 & 14,20 \\
\hline \multirow{2}{*}{ Tipos } & \multirow{2}{*}{ IFL } & \multirow{2}{*}{ IFF } & \multirow{2}{*}{ pH } & S S & EP & $\mathbf{F}$ \\
\hline & & & & ${ }^{\circ}$ Brix & $\mathrm{cm}$ & $\mathbf{N}$ \\
\hline Amarelo & $1,95 \mathrm{~b}$ & $1,28 \mathrm{~b}$ & $6,43 \mathrm{~b}$ & $13,45 \mathrm{a}$ & $3,59 \mathrm{a}$ & $45,01 \mathrm{a}$ \\
\hline Rendilhado & $1,81 \mathrm{~b}$ & $1,12 \mathrm{c}$ & $7,03 \mathrm{a}$ & $12,35 \mathrm{~b}$ & $3,49 \mathrm{a}$ & $31,96 \mathrm{c}$ \\
\hline Pele de sapo & $2,40 \mathrm{a}$ & $1,47 \mathrm{a}$ & $6,49 \mathrm{~b}$ & $13,15 \mathrm{a}$ & $3,66 \mathrm{a}$ & $40,10 \mathrm{~b}$ \\
\hline $\mathrm{CV}(\%)$ & 9,13 & 4,45 & 0,94 & 3,72 & 6,52 & 7,34 \\
\hline
\end{tabular}

*Médias seguidas de mesma letra na coluna não diferem entre si pelo teste de Tukey $(\mathrm{p}<0,05)$ 
pois estes apresentam diâmetros longitudinais inferiores. Nunes et al. (2011) e Santos et al. (2011) observaram valores de 16,3 a 24,2; 19,63 a 27,67 e 12,4 a 16,3 cm para diâmetro longitudinal do fruto, em melões dos tipos pele de sapo, rendilhado e amarelo, respectivamente. Diante dos resultados obtidos neste trabalho, verifica-se que os valores observados estão dentro da faixa de valores encontrada por esses autores, exceto para o melão tipo rendilhado, que apresentou diâmetro longitudinal do fruto menor.

No melão rendilhado, o índice de formato de fruto é menor que os dos tipos pele de sapo e amarelo, sendo que este tipo de melão (rendilhado) é mais arredondado, porque a diferença entre o diâmetro longitudinal e o diâmetro transversal do fruto é menor.

O melão tipo pele de sapo foi mais produtivo $(3,22 \mathrm{~kg}$ $\left.\mathrm{m}^{-2}\right)$ que os tipos amarelo $\left(2,30 \mathrm{~kg} \mathrm{~m}^{-2}\right)$ e rendilhado $(2,80$ $\mathrm{kg} \mathrm{m}^{-2}$ ) (Tabela 2). Essa diferença deve-se principalmente às características genéticas dos tipos testados. A produtividade encontrada neste trabalho para o tipo pele de sapo foi superior às obtidas por Nunes et al. (2011), que variaram de 11,90 a 26,67 tha ${ }^{-1}$. Em outro trabalho, Nunes et al. (2004), utilizando o cultivar Tendency, obtiveram uma produtividade de $28,58 \mathrm{t} \mathrm{ha}^{-1}$, ainda inferior à obtida para esse tipo de melão.

Para o tipo amarelo, a produtividade obtida está dentro da faixa obtida por Nunes et al. (2004), que variou de 19,59 a 32,54 t ha-1. No entanto, foi inferior às obtidas por Freitas et al. (2007), ao testar diferentes genótipos do tipo amarelo $\left(24,46\right.$ a 32,15 $\left.\mathrm{t} \mathrm{ha}^{-1}\right)$. A produtividade do melão tipo rendilhado foi semelhante à encontrada por Queiroga et al. (2008), que, ao variar o número e a posição de fixação dos frutos, observaram produtividade variando de 17,86 a 28,27 tha-1. No entanto, foi superior às verificadas por Charlo et al. (2009), que variou de 5,34 a $6,46 \mathrm{Kg} \mathrm{m}^{-2}$.

Com relação aos resultados de produtividade, verifica-se grande variação entre os diferentes tipos de melão nos trabalhos de pesquisa. Isto se deve, principalmente, ao ambiente, ao material genético utilizado e ao manejo efetuado na cultura durante seu ciclo.

O maior índice de formato do fruto $(1,47)$ foi observado para melão tipo pele de sapo (Tabela 2), sendo que, desta forma, seus frutos apresentaram formato alongado, que é característica típica dos cultivares desse tipo. De acordo com Purquerio \& Cecílio Filho (2005), essa característica é bastante importante, pois define a embalagem que será utilizada na comercialização. Esses autores relatam que frutos com índice de formato de fruto próximo de 1 (um) são preferidos, pois acima e abaixo deste valor dificultam seu arranjo nas embalagens. Sendo assim, os frutos pertencentes ao tipo rendilhado apresentaram o índice mais adequado.
Com relação ao pH, o maior valor foi observado para frutos do tipo rendilhado $(7,03)$, não havendo diferença estatística entre os tipos amarelo $(6,43)$ e pele de sapo $(6,49)$ (Tabela 2).

Para o tipo rendilhado, valores de $\mathrm{pH}$, semelhantes e inferiores aos obtidos neste estudo, foram encontrados por Melo et al. (2012) (7,1 e 8,0) e Charlo et al. (2009) (5,3 e 6,1), respectivamente.

Entre os tipos de melão, a maior média para o teor de sólidos solúveis foi obtida para os tipos amarelo e pele de sapo. De acordo com Silva et al. (2008), os frutos de melão devem ter no mínimo $9{ }^{\circ}$ Brix, para estarem de acordo com as normas internacionais. Na Tabela 2, verifica-se que os três tipos de melão apresentam teor de sólidos solúveis acima do mínimo recomendado para comercialização, sendo que o valor obtido para os melões do tipo pele de sapo foi superior ao obtido por Alves et al. (2000), que observaram um teor de sólidos solúveis de $11^{\circ}$ Brix.

Os valores de sólidos solúveis observados para os tipos pele de sapo $\left(13,15^{\circ} \mathrm{Brix}\right)$, rendilhado $\left(12,35^{\circ} \mathrm{Brix}\right) \mathrm{e}$ amarelo $\left(13,45^{\circ} \mathrm{Brix}\right)$ foram superiores aos obtidos por Nunes et al. (2011), que obtiveram média de $11,5^{\circ}$ Brix para linhagens de melão tipo pele de sapo, Castoldi et al. (2008), que, ao avaliarem híbridos de melão rendilhado, observaram valores de sólidos solúveis variando entre 9,00 e 11,24 ${ }^{\circ}$ Brix, e Nascimento Neto et al. (2012), que, ao avaliarem o efeito de doses e de formas de aplicação de nitrogênio em melão do tipo amarelo, obtiveram valores de sólidos solúveis variando de 8,5 a $12{ }^{\circ}$ Brix.

Neste experimento, foi observado que as plantas de melão do tipo pele de sapo eram mais vigorosas e tiveram o ciclo mais longo que, principalmente, o do tipo rendilhado. Essas observações podem explicar os maiores teores de sólidos solúveis encontrados para o tipo pele de sapo, pois, de acordo com Long et al. (2004), as plantas de meloeiro com atraso na polinização apresentam maior área foliar. Essa maior quantidade de massa foliar pode acumular e translocar mais fotoassimilados para os frutos, resultando em frutos mais doces.

Com relação à espessura da polpa, não foram observadas diferenças significativas entre os tipos de melão estudados (Tabela 2). Valores semelhantes aos deste trabalho foram obtidos por Nascimento Neto et al. (2012), Charlo et al. (2011) e Nunes et al. (2011), para espessura de polpa de melões do tipo amarelo $(3,15 \mathrm{~cm})$, rendilhado $(3,22 \mathrm{~cm})$ e pele de sapo $(4,2 \mathrm{~cm})$.

Para a característica firmeza de polpa, verificou-se diferença significativa entre os três tipos de melão (Tabela 2). O maior valor para firmeza de polpa foi de $45,01 \mathrm{~N}$ para o tipo amarelo e a menor firmeza de polpa foi observada para o tipo rendilhado com valor de $31,96 \mathrm{~N}$. 
Nunes et al. (2008) verificaram firmeza da polpa de híbridos de melão do tipo pele de sapo inferiores aos observados nesta pesquisa, encontrando valores de 22 a 28 N. O resultado para firmeza da polpa, encontrado neste trabalho, para melão tipo pele de sapo, também foi superior ao observado por Nunes et al. (2011), que, avaliando a produção e a qualidade de linhagens de melão, verificaram que a média da firmeza da polpa foi de 29,9 N. No entanto, Nunes et al. (2004) obtiveram valores semelhantes ao deste trabalho para melões do tipo pele de sapo $(39,20 \mathrm{~N})$ e com valores para o tipo amarelo variando de 26,65 a $40,05 \mathrm{~N}$.

Valores inferiores ao observado neste trabalho $(31,96$ N) foram verificados por Charlo et al. (2011), que, ao trabalharem com híbridos de melão do tipo rendilhado, em diferentes substratos, obtiveram valores de firmeza da polpa variando de 13 a 27 N, enquanto Freitas et al. (2007) observaram uma variação entre 17,91 a $26,08 \mathrm{~N}$, para híbridos de melão do tipo amarelo.

Segundo Filgueiras et al. (2001), os melões dos tipos amarelo, rendilhado e pele de sapo devem apresentar valores elevados de firmeza de polpa para terem boa conservação pós-colheita, sendo que o valor mínimo exigido no momento da colheita é de 24,30 e $32 \mathrm{~N}$, respectivamente. Os resultados obtidos para esta característica permitem afirmar que os três tipos de melão estudados apresentam vida longa de prateleira, permitindo, desta forma, chegar ao mercado consumidor com ótima textura.

O número de frutos por planta influenciou significativamente a massa média dos frutos, os diâmetros longitudinal e transversal do fruto, os diâmetros longitudinal e transversal do lóculo, a espessura da polpa, a produtividade, os sólidos solúveis e o $\mathrm{pH}$, de modo que, com exceção da produtividade, as plantas que foram mantidas com apenas um fruto apresentaram maiores valores para estas características (Tabela 3).

A massa média dos frutos e o número de frutos por planta são características que têm influência direta na produtividade. Nota-se que o aumento de um para dois frutos por planta reduziu a massa média dos frutos em 422,6 g (Tabela 3). Isto se deve à maior competição por fotoassimilados, haja vista que plantas com menos frutos fixados têm maior área foliar disponível para o crescimento individual dos frutos. Queiroga et al. (2008) observaram que plantas conduzidas com um fruto apresentaram maior acúmulo de massa nas folhas e caule, resultando em frutos com maior massa média, por causa da menor competição por fotoassimilados, favorecendo o acúmulo de matéria seca nos frutos.

Maior produtividade foi obtida em plantas que foram mantidas com dois frutos (Tabela 3), isto porque há uma compensação pelo maior número de frutos por planta e, consequentemente, por área. Esta observação também foi constatada por Queiroga et al. (2008) com o cultivar Torreon, quando o número de frutos por planta passou de um para dois, e por Seabra Júnior et al. (2003), trabalhando com plantas de melancia com um e dois frutos.

Para as variáveis relacionadas ao tamanho dos frutos, verificou-se a mesma tendência da massa média dos frutos, ou seja, frutos com maiores diâmetros longitudinal e transversal foram encontrados para plantas com apenas um fruto (Tabela 3). Esses resultados corroboram os obtidos por Queiroga et al. (2008), Seabra Júnior et al. (2003) e Fagan et al. (2006). Charlo et al. (2009) obtiveram valores para essas características de 13,24 a 13,45 cm, em trabalho em que as plantas foram mantidas com dois frutos. Fagan et al. (2006) atribuem esses resultados ao fato de que, ao aumentar a densidade de frutos por planta, aumenta-se a demanda de fotoassimilados pelos frutos e, em consequência disso, têm-se frutos com dimensões menores.

Com relação aos diâmetros longitudinal e transversal do lóculo, observa-se que frutos provenientes de plantas conduzidas com um fruto resultaram em maiores valores para estas características (Tabela 3). Essas variáveis dão a ideia do tamanho da cavidade interna, sendo que, quanto maior o fruto, maior será o tamanho do lóculo. Essa cavidade interna deve ser a menor possível, para conferir ao fruto resistência ao manuseio e ao transporte, impedindo o deslocamento da placenta, fato que antecipa a degradação do fruto, além de prolongar a vida útil póscolheita (Paiva et al., 2000).

$\mathrm{Na}$ Tabela 3, observa-se aumento da espessura da polpa em frutos de plantas com apenas um fruto $(3,80 \mathrm{~cm})$,

Tabela 3: Massa média dos frutos (MMF), diâmetro longitudinal do fruto (DLF), diâmetro transversal do fruto (DTF), diâmetro longitudinal do lóculo (DLL), diâmetro transversal do lóculo (DTL), espessura de polpa (EP), produtividade (PROD), sólidos solúveis (SS) e pH em função do número de frutos por planta

\begin{tabular}{|c|c|c|c|c|c|c|c|c|c|}
\hline \multirow{2}{*}{$\begin{array}{l}\text { Número } \\
\text { de frutos }\end{array}$} & MMF & DLF & DTF & DLL & DTL & $\mathbf{E P}$ & PROD & S S & \multirow{2}{*}{ pH } \\
\hline & $\mathbf{g}$ & cm & cm & $\mathrm{cm}$ & $\mathrm{cm}$ & $\mathrm{cm}$ & $\mathrm{Kg} \mathrm{m}^{-2}$ & ${ }^{\circ}$ Brix & \\
\hline Um fruto & $1473,84 \mathrm{a}$ & 16,87 a & $12,99 \mathrm{a}$ & $9,54 \mathrm{a}$ & $4,63 \mathrm{a}$ & $3,80 \mathrm{a}$ & $2,45 \mathrm{~b}$ & $13,48 \mathrm{a}$ & $6,69 a$ \\
\hline Dois frutos & $1051,22 \mathrm{~b}$ & $15,10 \mathrm{~b}$ & $11,70 \mathrm{~b}$ & $8,55 \mathrm{~b}$ & $4,21 \mathrm{~b}$ & $3,36 \mathrm{~b}$ & $3,09 \mathrm{a}$ & $12,48 \mathrm{~b}$ & $6,61 \mathrm{~b}$ \\
\hline$\overline{\mathrm{CV}(\%)}$ & 8,17 & 5,28 & 4,40 & 8,13 & 6,97 & 6,52 & 14,20 & 3,72 & 0,94 \\
\hline
\end{tabular}

*Médias seguidas de mesma letra na coluna não diferem entre si pelo teste de Tukey $(\mathrm{p}<0,05)$ 
em comparação com a de frutos de plantas com dois frutos $(3,36 \mathrm{~cm})$. Este resultado também está relacionado com a redução da competição por fotoassimilados. Purquerio \& Cecílio Filho (2005) observaram espessura de polpa de $3,10 \mathrm{~cm}$ para o híbrido Bonus 2, com dois frutos por planta, valor este semelhante ao obtido neste trabalho. Segundo Coelho et al. (2003), a espessura da polpa faz parte de um importante atributo de qualidade, pois é a parte comestível do fruto. Pequena cavidade interna e maior espessura de polpa são características do fruto de melão que o tornam mais valorizado e aceito pelo mercado (Paiva et al., 2000).

Frutos de plantas conduzidas com um fruto, comparados aos de plantas com dois frutos, apresentaram maiores médias para teor de sólidos solúveis e pH (Tabela 3). Queiroga et al. (2008), ao estudarem o efeito do número e da posição de fixação dos frutos na planta de meloeiro, observaram que frutos de plantas conduzidas com apenas um fruto apresentaram maior teor de sólidos solúveis que o dos frutos provenientes de plantas com dois frutos.

Segundo Costa et al. (2004), o aumento do número de frutos por planta reduz o teor de sólidos solúveis e essa redução é decorrente de menores disponibilidade e aporte desses fotoassimilados para o fruto, em razão da menor área foliar disponível por fruto. Esses mesmos autores relatam que a redução da competição por assimilados aumenta o teor de sólidos solúveis. Esta pode ser uma característica de grande importância na diferenciação do produto no mercado, principalmente por causa da preferência do consumidor por frutos mais doces.

\section{CONCLUSÕES}

A produtividade média foi maior nas plantas conduzidas com dois frutos. Por outro lado, as plantas conduzidas com um fruto apresentam maior massa média de frutos e maior espessura de polpa..

O índice de formato do fruto e o índice de formato de lóculo não foram influenciados pelo número de frutos mantidos por planta.

Independentemente do número de frutos mantidos por planta e do tipo de melão, o teor de sólidos solúveis foi superior ao mínimo recomendado para comercialização.

Melões do tipo pele de sapo apresentam maior massa média de frutos e produtividade que os demais tipos avaliados.

\section{AGRADECIMENTOS}

O trabalho recebeu apoio financeiro da Coordenação de Aperfeiçoamento de Pessoal de Nível Superior - CAPES.

\section{REFERÊNCIAS}

Ancelotti F \& Costa ND (2010) Sistema de Produção de Melão. Disponível em: <https://sistemasdeproducao.cnptia.embrapa.br/ FontesHTML/Melao/SistemaProducaoMelao/clima.html>. Acessado em: 23 de Janeiro de 2014.

Alves RE, Pimentel CR, Maia CE, Castro EB, Viana FM, Costa FV, Andrade GG, Filgueiras HAC, Almeida JHS, Menezes JB, Costa JG \& Pereira LSE (2000) Manual de melão para exportação. Brasília, Embrapa. 51p.

Castoldi R, Charlo HCO, Vargas PF \& Braz LT (2008) Qualidade de frutos de cinco híbridos de melão rendilhado em função do número de frutos por planta. Revista Brasileira de Fruticultura, 30:455-458.

Charlo HCO, Castoldi R, Vargas PF \& Braz LT (2009) Cultivo de melão rendilhadocom dois e três frutos por planta. Horticultura Brasileira, 27:251-255.

Charlo HCO, Galatti FS, Braz LT \& Barbosa JC (2011) Híbridos experimentais de melão rendilhado cultivados em solo e substrato. Revista Brasileira de Fruticultura, 33:144-156.

Chitarra MIF \& Chitarra AB (2005) Pós-colheita de frutos e hortaliças: fisiologia e manuseio. Lavras, UFLA. 783p.

Coelho EL, Fontes PCR, Finger FL \& Cardoso AA (2003) Qualidade do fruto de melão rendilhado em função de doses de nitrogênio. Bragantia, 62:173-178.

Costa CC, Cecílio Filho AB, Cavariani RL \& Barbosa JC (2004) Concentração de potássio na solução nutritiva e a qualidade e o número de frutos de melão por planta em hidroponia. Ciência Rural, 34:731-736.

Fagan EB, Medeiros SLP, Simon J, Luz GL, Borcioni E, Jasniewicz LR, Casaroli D \& Mafron PA (2006) Evolução e partição de massa seca do meloeiro em hidroponia. Acta Siencia Agronomy, 28:165-172.

Ferreira DF (2011) Sisvar: a computer statistical analysis system. Ciência e Agrotecnologia, 35:1039-1042.

Filgueira FAR (2008) Novo Manual de olericultura. Viçosa, UFV. $402 \mathrm{p}$.

Filgueiras HAC, Menezes JB, Alves RE, Costa FV, Pereira LSE \& Júnior JG (2001) Frutas do Brasil: melão pós-colheita. Brasília, Embrapa-SPI. 41p.

Freitas JG, Crisóstomo JR, Silva FP, Pitombeira JB \& Távora FJAF (2007) Interação entre genótipo e ambiente em híbridos de melão Amarelo no Nordeste do Brasil. Revista Ciência Agronômica, 38:176-181.

Godoy AR \& Cardoso AII (2003) Curva de crescimento e qualidade de frutos de melão rendilhado sob cultivo protegido. Revista Ceres, 50:220-303.

IBGE - Instituto Brasileiro de Estatística e Geografia (2012) Estados. Disponível em: <http://www.ibge.gov.br/estados/>. Acessado em: 10 de abril de 2013.

Instituto Adolfo Lutz (2005) Métodos Físico-Químicos para Análise de Alimentos. Brasília, Ministério da Saúde, Agência Nacional de Vigilância Sanitária. 1018p.

Long RL, Walsh KB, Rogers G \& Midmore DJ (2004) Source-sink manipulation to increase melon (Cucumis melo L.) fruit biomass and soluble sugar content. Australian Journal of Agricultural Research, 55:1241-1251.

Melo DM, Castoldi R, Charlo HCO \& Braz LT (2012) Produção e qualidade de melão rendilhado sob diferentes substratos em cultivo protegido. Revista Caatinga, 25:58-66. 
Nascimento Neto JR, Bomfim GV, Azevedo BM, Viana TVA \& Vasconcelos DV (2012) Formas de aplicação e doses de nitrogênio para o meloeiro Amarelo no litoral do Ceará. Irriga, 17:364375

Nunes GHS, Santos Júnior JJS, Andrade FV, Bezerra Neto F, Almeida AHB \& Medeiros DC (2004) Aspectos produtivos e de qualidade de híbridos de melão cultivados no agropolo Mossoró-Assu. Horticultura Brasileira, 22:744-747.

Nunes GHS, Pereira EWL, Sales Junior R, Bezerra Neto F, Oliveira KC \& Mesquita LX (2008) Produtividade e qualidade de frutos de melão pele-de-sapo em duas densidades de plantio. Horticultura Brasileira, 26:236-239.

Nunes GHS, Costa Filho JH, Silva DJH, Carneiro PCS \& Dantas MSM (2011) Divergência genética entre linhagens de melão pele de Sapo. Revista Ciência Agronômica, 42:765-773.

Paiva WO, Hassan Neto S \& Lopes AGS (2000) Avaliação de linhagens de melão. Horticultura Brasileira, 18:109-113.

Purquerio LFV \& Cecílio Filho AB (2005) Concentração de nitrogênio na solução nutritiva e número de frutos sobre a qualidade de frutos de melão. Horticultura Brasileira, 23:831-836.

Queiroga RCF, Puiatti M, Fontes PCR \& Cecon PR (2008) Produtividade e qualidade do melão cantaloupe, cultivado em ambiente protegido, variando o número e a posição dos frutos na planta. Bragantia, 67:911-920.
Santos AF, Costa CC, Silva FVG, Bezerra e Silva RM \& Medeiros LL (2011) Qualidade de melão rendilhado sob diferentes doses nutricionais. Revista Verde, 6:134-145.

Seabra Júnior S, Pantano SC, Hidalgo AH, Rangel MG \& Cardoso AII (2003) Avaliação do número e posição de frutos de melancia produzidos em ambiente protegido. Horticultura Brasileira, 21:708-711.

Silva EO, Alves RE \& Santos EC (2008) Colheita e pós-colheita na produção integrada de melão. In: Braga Sobrinho R, Guimarães JA, Freitas J de $\mathrm{AD}$ de, Terao D (Eds.) Produção Integrada de Melão. Fortaleza, Embrapa Agroindútria Tropical. p.273284 .

Trani PE, Tivelli SW \& Carrijo AO (2011) Fertirrigação em hortaliças. Campinas, Instituto Agronômico. 58p. (Boletim técnico IAC, 196).

Vargas PF, Galatti FS, Souza JO, Castoldi R, Charlo HCO \& Braz LT (2013) Características físico-químicas de frutos de híbridos experimentais de melão rendilhado. Horticultura Brasileira, 31:351-355. 